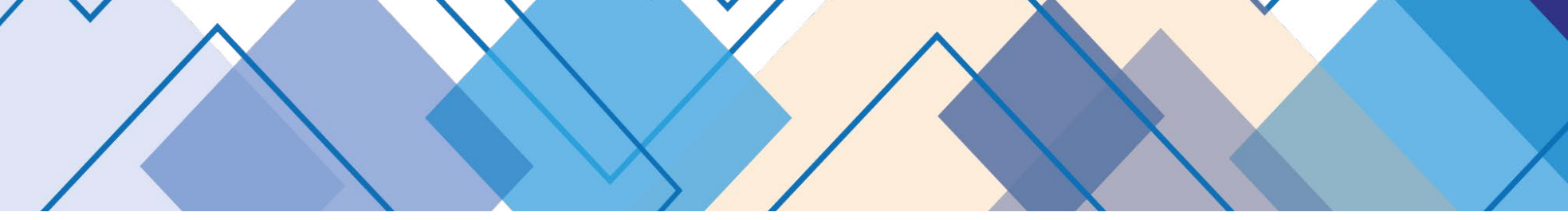

\title{
PROJETOS INTEGRADORES E A EXPERIÊNCIA INOVADORA DO LABORATÓRIO DE PRÁTICAS PROFISSIONAIS NO CURSO SUPERIOR DE TECNOLOGIA EM ANÁLISE E DESENVOLVIMENTO DE SISTEMAS
} INTEGRATING PROJECTS AND THE INNOVATIVE EXPERIENCE OF THE PROFESSIONAL PRACTICE LABORATORY OF THE UNDERGRADUATE TECHNOLOGICAL COURSE OF SYSTEM ANALYSIS AND DEVELOPMENT PROYECTOS INTEGRADORES Y LA EXPERIENCIA INNOVADORA DEL LABORATORIO DE PRÁCTICAS PROFESIONALES EN EL CURSO SUPERIOR DE TECNOLOGÍA EN ANÁLISIS Y DESARROLLO DE SISTEMAS

\section{Letícia Ester Cruz Silva* \\ Johnny Edward \\ Villavicencio Tafur* *}

*Pedagoga, Especialista em Psicopedagogia, em Gestão

Educacional, em Educação

a Distância e em Docência

na Educação Profissional.

Coordenadora da equipe responsável pela Formação Continuada de

Docentes no Senac RJ. Rio de

Janeiro, Rio de Janeiro, Brasil. E-mail: leticia.ester@senac.br

**Engenheiro de Computação, Doutor em Ciência da Computação, Professor de Ensino Superior.

Coordenador do curso de

Graduação Tecnológica em Análise e Desenvolvimento de Sistemas na

Faculdade Senac RJ. Niterói, Rio de Janeiro, Brasil. E-mail: johnny. tafur@rj.senac.br

Recebido para publicação em: 11.7.2019

Aprovado em 18.12.2019

\section{Resumo}

Este trabalho apresenta a experiência da utilização da estratégia metodológica Laboratório de Práticas Profissionais, realizada na Graduação Tecnológica em Análise e Desenvolvimento de Sistemas da Faculdade de Tecnologia Senac Rio. Analisa em que medida o Laboratório possibilitou que os estudantes desenvolvessem e consolidassem as competências previstas, na busca de solução a um desafio concreto, ao articular e integrar todos os módulos do curso para atender a uma demanda real trazida por uma empresa de consultoria e gestão de software para gerenciamentos de navios na área de offshore.

Palavras-chave: Desenvolvimento de competências. Prática profissional. Protagonismo do estudante. Projeto integrador.

\section{Abstract}

This work presents the experience of employing the Laboratory of Professional Practices methodological strategy at the undergraduate technological course of System Analysis and Development at Senac Rio. It analyzes to what extent the Laboratory allowed students to develop and consolidate the expected competencies in the search for a solution to a concrete challenge, by articulating and integrating all course modules to meet the real demands brought by software management and the consulting company regarding the management of an offshore vessel. 
Keywords: Competency development. Professional practice. Student protagonism. Integrating project.

\section{Resumen}

Este trabajo presenta la experiencia de la utilización de la estrategia metodológica Laboratorio de Prácticas Profesionales, realizada en la Graduación Tecnológica en Análisis y Desarrollo de Sistemas de la Facultad de Tecnología Senac Río. En él, se analiza el grado en el cual el Laboratorio permitió que los estudiantes desarrollaran y consolidaran las capacidades previstas, en busca de la solución a un desafío concreto. Para esto, se articularon e integraron todos los módulos del curso para dar respuesta a una demanda real traída por una empresa de consultoría y gestión de sistemas informáticos para la administración de navíos en el área de offshore.

Palabras clave: Desarrollo de competencias. Práctica profesional. Protagonismo del estudiante. Proyecto integrador.

\section{Introdução}

A proposta de uma aula com o foco em desenvolvimento de competências muda radicalmente a ação docente
As Diretrizes Curriculares Nacionais Gerais para a organização e o funcionamento dos cursos superiores de tecnologia, por meio da Resolução CNE/CP n. 03/2002, conceituam competência profissional como "a capacidade pessoal de mobilizar, articular e colocar em ação conhecimentos, habilidades, atitudes e valores necessários para o desempenho eficiente e eficaz de atividades requeridas pela natureza do trabalho e pelo desenvolvimento tecnológico" (CONSELHO NACIONAL DE EDUCAÇÃO, 2002, p. 162). A Resolução determina que esses cursos apresentem em seus projetos o perfil profissional de conclusão, definindo claramente as competências profissionais a serem desenvolvidas (CONSELHO NACIONAL DE EDUCAÇÃO, 2002).

Tal determinação acaba por direcionar todas as ações a serem realizadas na oferta, desde a criação do projeto do curso até a certificação, passando pelo plano de ensino a ser elaborado pelos professores e disponibilizado à comunidade acadêmica e, principalmente, pelo planejamento, pela mediação e pela avaliação do processo de ensino e aprendizagem.

A proposta de uma aula com o foco em desenvolvimento de competências muda radicalmente a ação docente, que coloca o aluno como o protagonista do processo de aprendizagem a partir de estratégias que utilizam desafios e problemas para o desenvolvimento e a consolidação das competências previstas nos cursos. O fazer docente se estrutura de modo que não se separa teoria e prática, com a aplicação dos conteúdos nas soluções de situações similares às que os indivíduos encontrarão na atuação profissional. Perrenoud (1999, p. 26) explica que a construção de conhecimentos sem aplicação não resulta em uma formação efetiva e significativa: 
"[...] a maioria dos conhecimentos acumulados na escola permanece inútil na vida cotidiana, não porque careçam de pertinência, mas porque os alunos não aprenderam a utilizá-los em situações concretas".

A fala de Perrenoud diz respeito à prática pedagógica que não prioriza a aplicação das bases teóricas, na qual o estudante aprende os conteúdos, mas não sabe como aplicá-los em situações na vida cotidiana e, nesse caso, na rotina do mundo laboral. Isso ocorre com aulas nas quais as atividades de ensino são descontextualizadas e, geralmente, com a utilização de exercícios meramente para memorização de conteúdo.

A Resolução CNE/CP n. 03/2002, ao dispor dessa prerrogativa para a Educação Superior Tecnológica, visa garantir que o egresso tenha condições de adentrar e ter sustentabilidade em um ambiente competitivo, no qual a inovação tecnológica define o processo produtivo e de trabalho e no qual as empresas buscam profissionais atualizados, que ofereçam soluções imediatas aos mais variados problemas constantes da rotina das diversas áreas de prestação de serviços. Não faria sentido que a formação oferecida não proporcionasse ao indivíduo condições para desempenhar as funções da ocupação escolhida.

A inovação tecnológica define 0 processo produtivo e de trabalho

Masi (2006) alertou sobre a influência das inovações tecnológicas, que modificariam a estrutura piramidal posta pelos princípios de padronização da organização industrial. Esse modo operante do mundo do trabalho, que propõe uma inserção mais rápida no sistema produtivo atual, impulsiona a disputa pelo Ensino Superior Tecnológico, o qual demanda atualização científica e tecnológica, além de habilidades para se adaptar ao novo.

As instituições que ofertam cursos superiores de Tecnologia propõem alternativas para atender à Resolução CNE/CP n. 03/2002. No Senac, a adoção de uma metodologia com foco em desenvolvimento de competências direciona a atuação de especialistas, corpo técnico e corpo docente na busca de soluções educacionais que possibilitem uma formação que acompanhe as demandas do mundo do trabalho e que formem indivíduos com condições de manter a atividade profissional com as competências requeridas pelo cenário atual. Esse perfil profissional requerido na atualidade exige uma proposta pedagógica diferenciada, pois

Para responder a esses novos desafios, é fundamental superar a forma tradicional de educação profissional, baseada na execução operacional de tarefas, sendo, portanto, requerida uma compreensão mais ampla do processo produtivo, além do domínio operacional de suas habilidades técnicas (CORDÃO; MORAES, 2017, p. 31).

Nessas circunstâncias, as soluções e estratégias educacionais devem resultar na formação de profissionais capazes de articular e transferir aprendizagens para os desafios com os quais se defrontarão na rotina do mundo do trabalho. Em um processo de ensino na perspectiva do desenvolvimento de competências, a prática pedagógica transforma a sala de aula em um laboratório no qual os conhecimentos científicos são aplicados na solução de problemas e em desafios relacionados à ocupação em questão. 
Assim, este artigo busca delinear reflexões acerca do Laboratório de Práticas Profissionais como estratégia didática para o alcance efetivo dos resultados esperados do processo de ensino e aprendizagem, na perspectiva de integração de todos os módulos do curso. Mais especificamente, analisou-se como o Laboratório é utilizado na área de Tecnologia da Informação, avaliando sua aplicação no curso de Graduação Tecnológica em Análise e Desenvolvimento de Sistemas da Faculdade de Tecnologia Senac Rio'.

\section{0 Laboratório de Práticas Profissionais}

O Laboratório de Práticas Profissionais foi implantado no Senac RJ para viabilizar a efetivação da metodologia adotada por esta Instituição, focada em desenvolvimento de competências, com a finalidade de proporcionar aos alunos o exercício profissional em situações concretas e desafiadoras.

Essa estratégia pedagógica foi proposta para garantir a articulação das competências desenvolvidas nos cursos, a aplicação das bases tecnológicas de forma integrada, o protagonismo do aluno no processo de aprendizagem e a aproximação do Senac com as empresas do setor do Comércio de Bens, Serviços e Turismo. A participação ativa do estudante acontece por meio da pesquisa, da interpretação de dados e informações, da busca por conhecimentos, questionamentos, experimentação, criação e registro de hipóteses e do acompanhamento do seu desenvolvimento com base nos feedbacks dos docentes a cada atividade realizada (FREITAS; NORI, 2014).

Sendo executado no âmbito dos Projetos Integradores², o Laboratório de Práticas Profissionais visa mobilizar os estudantes a criar soluções inovadoras às demandas trazidas por empresas e organizações, possibilitando, assim, a efetiva formação profissional dos estudantes, por meio da aplicação do conhecimento em situação real de trabalho. Nessa proposta, o estudante é desafiado a atuar em um projeto de mercado, no qual há um demandante real à procura de uma solução para um problema ou necessidade da empresa.

O Laboratório de Práticas Profissionais traz para o processo de ensino a aprendizagem por meio da própria ação dos estudantes sobre um determinado objeto - uma solução ou problema - pelo qual os alunos são instigados a construir soluções inovadoras. Abordar problemas atuais e reais melhora a forma de enfrentar e combater os problemas futuros, além de favorecer a construção de competências (FREITAS; NORI, 2014). Sua metodologia prevê etapas fundamentais para a sua execução, conforme descrito por Freitas e Nori (2014):

1. Contexto de mercado: na qual ocorre a prospecção de empresas e identificação de oportunidades. 
2. Contexto de desenvolvimento: seleção do curso, Unidade Operativa e a turma que assumirá a demanda identificada, em função da agenda e do planejamento das aulas.

3. Reunião do coordenador do curso com o docente do Projeto Integrador e definição de custos ou investimentos: todas as decisões tomadas devem ser registradas no diário de bordo.

4. Assinatura do termo de acordo: as partes assinam um documento com as responsabilidades descritas.

5. Reunião do coordenador do curso com o docente do Projeto Integrador e demais docentes do módulo ou curso, quando são apresentados os objetivos da demanda da empresa parceira e os resultados esperados. Nessa etapa também são validados o plano de trabalho e o cronograma de execução do projeto.

6. Operação do Laboratório de Práticas Profissionais: inicia-se a partir de uma reunião com os estudantes para a apresentação da demanda, do plano de trabalho e dos resultados esperados.

A seguir, o esquema que mostra a estrutura analítica do Laboratório de Práticas Profissionais.

\section{Figura 1 - Estrutura analítica do Laboratório de Práticas Profissionais}

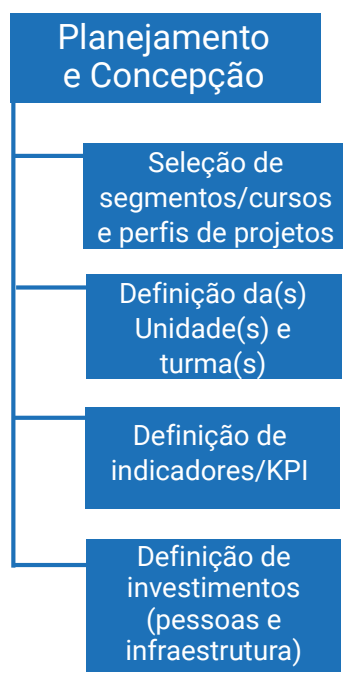

Fonte: Freitas; Nori (2014)

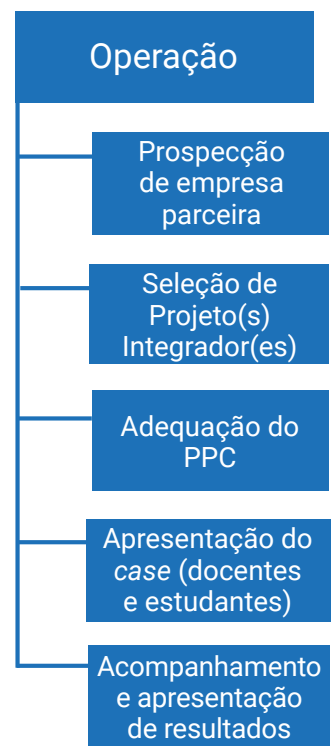

O Laboratório de Práticas Profissionais em questão foi aplicado no segundo semestre de 2018, de forma inovadora na Graduação Tecnológica em Análise e Desenvolvimento de Sistemas ${ }^{3}$. Por meio de um trabalho conjunto de todos os Projetos Integradores e pela convicção de que o projeto pedagógico do curso é alinhado e aderente 
ao perfil do profissional no mercado de trabalho, propôs-se a integração dos módulos no atendimento a uma necessidade ou desafio real, para que os estudantes vivenciassem a atuação do profissional na ocupação do modo mais fidedigno possível.

A experiência relatada, inovadora e inédita no curso de Análise e Desenvolvimento de Sistemas, teve como proposta a integração das competências de todos os módulos do curso para a execução de um projeto de desenvolvimento de software em um desafio real, tal e como as empresas do mercado realizam essa mesma atividade. Assim, o questionamento a ser respondido é: o Laboratório de Práticas Profissionais realizado com a articulação de todos os módulos do curso Análise e Desenvolvimento de Sistemas possibilita que os estudantes consolidem e articulem as competências desenvolvidas no curso?

\section{Objetivos da vivência}

A capacitação

para o trabalho requer a formação de profissionais que atendam às necessidades do atual contexto organizacional
O ambiente empresarial requer profissionais cada vez mais diferenciados no que diz respeito a uma atuação crítica e criativa para intervir no processo de produção e comercialização de bens, produtos e serviços. Segundo Rehem (2009, p. 56), "nos cenários que marcam o trabalho na contemporaneidade e que exigem novas capacidades aos trabalhadores, a educação para aprender a trabalhar tem, necessariamente, novas funções a cumprir, novos desafios a enfrentar".

Por assim ser, a busca de metodologias educacionais que proponham uma aprendizagem não somente focada em saber conceitos e conteúdos, mas na aplicação destes de forma significativa e inovadora tem sido uma constante para educadores e agentes formadores que possuem um compromisso com a empregabilidade do egresso, pois a capacitação para o trabalho requer a formação de profissionais que atendam às necessidades do atual contexto organizacional.

Nesse sentido, propor metodologias de ensino com práticas inovadoras, que atendam às exigências atuais, torna-se fundamental para a permanência e relevância das instituições formadoras na sociedade contemporânea. Mas a simples adoção de práticas educativas diferenciadas não garante que os agentes formadores estejam cumprindo o seu propósito. A verificação do quanto uma metodologia cumpre o que se espera dela se faz necessária para que seja ajustada, se forem identificadas oportunidades de melhorias, para em seguida serem validadas e replicadas.

o Senac possui uma proposta pedagógica com o foco em desenvolvimento de competências, o que por si só já o diferencia de outras instituições, visto ser uma metodologia que propõe ao estudante situações desafiadoras, similares às que encontrarão no mundo do trabalho. A prática docente utiliza estudos de caso, simulações e outras estratégias de ensino que demandam análise e nas quais os conteúdos são utilizados para a elaboração de soluções. A realização do Laboratório de 
Práticas Profissionais proporciona que os estudantes apliquem os conhecimentos e articulem as competências do curso em situações reais.

Os professores dos Projetos Integradores do curso de Análise e Desenvolvimento de Sistemas receberam o desafio de trabalhar de forma conjunta com o objetivo de criação de um sistema de software real para uma empresa de consultoria e gestão de software para gerenciamento de navios na área de offshore.

O desenvolvimento de um projeto de software requer diversas fases e responsabilidades, que estão definidas no ciclo tradicional de desenvolvimento desse tipo de programa. Para alcançar esse objetivo em um espaço curto de tempo, foi utilizada a estrutura dos Projetos Integradores do curso de Análise e Desenvolvimento de Sistemas, que é composto de modo que atenda às etapas do ciclo de desenvolvimento de software.

As fases necessárias à construção da proposta de solução à empresa foram assim definidas: modelagem do sistema utilizando a metodologia Unified Modeling Language (UML); construção de algoritmos e banco de dados; criação de interfaces com adequadas características de usabilidade e acessibilidade; programação frontend e backend; desenvolvimento mobile; e gerência de projetos utilizando metodologias ágeis.

Para atender às exigências de cada uma das fases definidas para o desenvolvimento de um projeto de software, citadas anteriormente, foi determinado que a entrega solicitada pela empresa aconteceria com a participação de todos os Projetos Integradores do curso, de forma conjunta, em que o Projeto Integrador de cada módulo atenderia a uma das responsabilidades do projeto de acordo com as competências definidas no Projeto Integrador do seu módulo. Esse foi um grande desafio que a equipe docente do curso assumiu e que implicava um compromisso de entrega a uma empresa parceira da Instituição.

Desse modo, a turma no módulo 1 ficou encarregada de criar a documentação técnica do sistema, assim como a projeção do sistema baseado na orientação a objetos; a turma no módulo 2 ficou responsável por arquitetar o banco de dados relacional e pelo mapeamento dos processos de desenvolvimento de software; os estudantes do módulo 3 foram responsáveis por implementar o banco de dados e a construção de interfaces web acessíveis, desenvolvendo o sistema considerando as boas práticas de qualidade de software; os estudantes no módulo 4 foram responsáveis por levantar requisitos, mensurar o esforço do projeto, acompanhar a gerência da atividade e desenvolver aplicações computacionais; e os estudantes no módulo 5 ficaram responsáveis pela gerência do projeto utilizando metodologias ágeis, integrando o resultado do trabalho de todas as equipes e realizando o alinhamento estratégico entre os objetivos do cliente e as ações de execução do projeto.

A problemática foi apresentada aos estudantes no início das aulas, no segundo semestre de 2018. A demanda de desenvolvimento de um sistema foi feita pela empresa Avancer, que atua na área de consultoria em desenvolvimento de sistemas para navios offshore. 
O demandante foi convidado a participar de uma reunião com todos os estudantes do curso e explicou detalhadamente as dificuldades da empresa. Os estudantes ouviram e, juntamente com os professores das Unidades Curriculares Projetos Integradores, elaboraram um plano de ação para o desenvolvimento do projeto de software, que seria o produto que solucionaria o problema apresentado.

Ao longo da execução das etapas do plano de ação, a empresa esteve presente em algumas aulas, fornecendo informações e realizando o checkpoint do que estava sendo desenvolvido e os alunos puderam interagir com os colegas mais experientes, dos módulos mais adiantados, dado que a proposta foi articular e integrar as turmas dos cinco módulos do curso, trabalhando de forma conjunta no desenvolvimento da solução para um problema.

A proposta do trabalho com a integração e articulação de todos os Projetos Integradores do curso demandou que existisse um alinhamento preciso e fundamentado com todas as unidades curriculares do curso, porque é a partir da contribuição de cada unidade curricular que a proposta do Projeto Integrador é construída e efetivada. O produto-final apresentado pelos estudantes foi um software de gerenciamento e controle de navios, com um sistema de extração de dados de sensores em equipamentos, para posteriormente serem enviados pela internet para um outro sistema, que coleta os dados em um centro de controle e apresenta essas informações em diversos painéis de informações. O software teria o objetivo de contribuir para que os operadores do centro de controle pudessem tomar decisões rapidamente ante um evento de alarme de cada navio da frota.

0 produto-final apresentado pelos estudantes foi um software de gerenciamento e controle de navios
Quando foi solicitado esse sistema, a empresa parceira informou que, no Brasil, não existia um software com essas características e a construção desse tipo de sistema abriria um nicho de mercado para profissionais que poderiam melhorar ou dar manutenção a esse tipo de negócio.

Após quatro meses de trabalho intenso, no dia 13 de dezembro de 2018, os estudantes apresentaram as soluções encontradas para os representantes da empresa, o que resultou em grandes elogios pela forma como um curso inteiro conseguiu desenvolver um programa, atendendo às diversas etapas reais de projeto de desenvolvimento de software.

Além disso, a empresa avultou a importância de os alunos vivenciarem a experiência de participação em um projeto no qual diversas pessoas trabalham de forma conjunta, em situações e experiências que só podem ser vistas quando se faz parte de uma equipe real uma equipe real de trabalho. Destacou que a metodologia de ensino utilizada pelo Senac é um enorme diferencial na formação, pois os estudantes saem do curso com essa experiência, o que é levado em consideração no momento de serem selecionados para uma vaga no mercado de trabalho.

A proposta de realizar o Projeto Integrador com todos os módulos do curso teve diversos desafios, o principal deles foi conseguir unir e gerenciar o trabalho conco- 
mitante dos cinco módulos do curso de Graduação Tecnológica de Análise e Desenvolvimento de Sistemas, que deveria convergir para a solução que se buscava, além de criar tarefas para cada módulo de acordo com as competências a serem desenvolvidas nas Unidades Curriculares e que deveriam ser articuladas nos Projetos Integradores. O motivo da escolha desse desafio foi permitir a vivência dos alunos em trabalhar em um projeto de desenvolvimento de software para uma demanda real e de forma inovadora, pois os estudantes acompanhariam as entregas dos demais Projetos Integradores do curso, além do que estava sob a responsabilidade da sua turma.

Conforme relato dos professores do curso, durante a execução do projeto, foram encontradas diversas dificuldades, por exemplo a sincronização na indicação de tarefas para os grupos por parte dos professores, dado que, em diversas ocasiões, não dispõem de um ambiente com capacidade para reunir todas as equipes para alinhar as entregas das etapas do projeto. Essa dificuldade foi superada graças ao uso de ferramentas de compartilhamento de informações e gerenciamento de projetos.

\section{Metodologia}

Na presente pesquisa, buscou-se analisar o quanto a proposta metodológica inovadora aplicada no Laboratório de Práticas Profissionais possibilitou o desenvolvimento das competências previstas no curso em questão. Para quantificar o fenômeno em estudo, buscando o nível de atendimento que se espera do Laboratório de Práticas Profissionais, foi utilizado um questionário para obter a percepção dos alunos envolvidos. A escolha por esse dispositivo se deu pelo entendimento de que o questionário, como instrumento avaliativo para a coleta de dados, possibilita a investigação de fatos, comportamentos, opiniões, expectativas, interesses, preferências e situações vivenciadas, por intermédio de uma quantidade de questões utilizadas para a averiguação, conforme explicam Elliot, Hildenbrand e Berenger (2012). O questionário foi elaborado com quatro questões fechadas e duas questões abertas, visando trazer, além da resposta ao questionamento que direciona o estudo, a percepção irrestrita dos respondentes em relação ao objeto observado.

Foram determinados padrões de avaliação em função da ocorrência das respostas positivas dos respondentes, conforme detalhado no Quadro 1.

\section{Quadro 1 - Padrões de Avaliação}

\begin{tabular}{|l|l|}
\hline Incidência de respostas positivas nas questões estruturadas & Padrão \\
\hline Acima de $70 \%$ & Atende \\
\hline Entre $50 \%$ e $69 \%$ & Atende parcialmente \\
\hline Abaixo de $50 \%$ & Não atende \\
\hline
\end{tabular}

Fonte: Os autores (2019). 
Foram convidados a participar 47 estudantes, dos quais, 27 responderam o questionário. Os respondentes foram orientados a acessar um link, que os direcionou ao questionário inserido no aplicativo Google Forms, o qual é uma ferramenta que permite a criação de formulários e está disponível no Google Apps para os usuários do Gmail, conforme as informações contidas no site da empresa $G$ Suit by Google Cloud.

Essa tecnologia possibilita a coleta de dados via formulários e facilita a análise das informações obtidas, pois apresenta os resultados de questões objetivas com gráficos e relaciona as respostas das questões discursivas para serem analisadas posteriormente. Além disso, facilita que pessoas com dificuldade para salvar, preencher e enviar arquivos participem de pesquisas e estudos que demandam coleta de dados em estudos que envolvem uma quantidade razoável de respondentes, pois os questionários são respondidos automaticamente no link indicado no texto enviado por e-mail.

\section{Resultados e discussões}

Os dados fornecidos nas questões estruturadas foram analisados com a utilização dos padrões apresentados no Quadro 1, estabelecidos para a ocorrência de respostas positivas.

O conteúdo coletado nas questões discursivas foi analisado qualitativamente. Foi feita a análise centrada em temas que, conforme Earp e Hildenbrand (2018 apud Silva, 2018, p. 90), "são unidades de significação que se colocam em evidência na análise dos textos em conformidade aos critérios relacionados à teoria que orienta o processo de leitura". Essa definição é corroborada por Minayo (2006, p. 209):

A análise temática se encaminha para a contagem de frequência das unidades de significação como definidoras do caráter do discurso. Ou, ao contrário, qualitativamente a presença de determinados temas denota os valores de referência e os modelos de comportamento presentes no discurso.

A análise dos dados permitiu que a questão avaliativa do estudo fosse respondida e, ainda, definidas as recomendações, direcionadas à coordenação do curso e à equipe pedagógica da Faculdade de Tecnologia Senac Rio, quanto aos aspectos pontuados pelos respondentes, principalmente nas questões discursivas.

As perguntas dois e três do questionário tiveram o objetivo de responder à questão direcionadora do estudo. São elas: "Ao realizar as atividades propostas no projeto, você utilizou as aprendizagens construídas durante o curso?" e "Você considera que o projeto possibilitou que as competências previstas no curso fossem desenvolvidas e consolidadas?".

Essas questões receberam, respectivamente, $85,2 \%$ e $74,1 \%$ de respostas positivas, trazendo a conclusão de que a metodologia inovadora utilizada no Laboratório de Práticas Profissionais do curso Análise e Desenvolvimento de Sistemas, realizado 
com a articulação de todos os módulos do curso, possibilitou que os estudantes desenvolvessem e consolidassem as competências previstas, com a aplicação dos conhecimentos aprendidos durante o curso. Os demais resultados, que foram relevantes para a análise mais ampla do objeto do estudo, estão descritos a seguir.

A primeira pergunta, que recebeu $92,6 \%$ de respostas positivas, questionou se o desafio proposto pela empresa Avancer e as entregas previstas nas etapas de execução do Plano de Ação estavam relacionados ao Projeto Integrador do respectivo módulo.

O resultado obtido mostra a adequação da demanda aos Projetos Integradores e módulos do curso, o que é satisfatório para a equipe de professores e coordenadores que acompanharam o projeto e que decidiram assumir a demanda. A obtenção de 81,5\% de respostas positivas na quinta pergunta - "A experiência do Projeto Integrador no atendimento à demanda da empresa Avancer proporcionou que você vivenciasse uma situação real do mundo do trabalho na área do seu curso?" - explicitou que o Laboratório de Práticas Profissionais cumpriu seu propósito nessas turmas, ou seja, assegura que o estudante seja o protagonista do processo de aprendizagem quando vivencia situações nas quais responderá a desafios reais do mundo do trabalho.

Já nas questões quatro e seis, os estudantes justificaram as respostas negativas à terceira questão e puderam pontuar o que não havia sido abordado no instrumento. Assim, na quarta questão os respondentes registraram suas justificativas para a resposta negativa à pergunta anterior, a qual indagou se o projeto realizado possibilitou que as competências previstas no curso fossem desenvolvidas e consolidadas.

O resultado da análise de conteúdo apontou que alguns estudantes do primeiro módulo do curso sentiram dificuldade ou receio ao assumir tamanha responsabilidade com o desafio, que era real. Também houve registro de que o tempo para as tarefas foi curto diante de muitas cobranças. Um estudante registrou a falta de clareza da empresa no relato da necessidade.

Na última questão, na qual foi dada a oportunidade de pontuarem o que achassem pertinente e que não havia sido abordado no instrumento, novamente foi registrada a necessidade de tempo maior para as entregas e realizações das tarefas. Houve também o reforço de que o desafio foi excessivo para os estudantes do primeiro módulo, os quais estavam se adaptando à vida acadêmica.

\section{Considerações finais}

A análise da execução do Laboratório de Práticas Profissionais na Graduação Tecnológica em Análise e Desenvolvimento de Sistemas da Faculdade de Tecnologia Senac Rio em uma perspectiva inovadora, que integrou os cinco módulos do curso na busca de solução ao desafio apresentado por uma empresa de consultoria em desenvolvimento de sistemas para navios offshore, chamada Avancer, suscitou algumas considerações. 
Ao longo do desenvolvimento do projeto, os estudantes articularam todas as competências previstas no Projeto Integrador do respectivo módulo que estavam cursando, assim como tiveram a oportunidade de ver como as competências dos Projetos Integradores dos outros módulos têm função fundamental para a execução de um projeto de software.

Do mesmo modo, os estudantes puderam verificar a relevância das competências desenvolvidas durante o curso, quando aplicaram as aprendizagens construídas na concepção da solução, pois vivenciaram a experiência de desenvolvimento de um software que atenderia a uma necessidade real.

\section{0 processo}

de ensino foi

enriquecido

com o emprego

de uma prática

sociointeracionista

A inovação proporcionada pelo Laboratório de Práticas Profissionais executada com a união dos cinco Projetos Integradores do curso para a busca da solução a ser apresentada para o problema levado pela empresa foi positiva e fundamental para que os estudantes trocassem experiências que não fariam se cada turma executasse o Projeto Integrador de seu módulo separadamente, atendendo a um demandante distinto. O processo de ensino foi enriquecido com o emprego de uma prática sociointeracionista, que potencializou a aprendizagem e o desenvolvimento das competências previstas no curso.

A metodologia aplicada no Laboratório de Práticas Profissionais no âmbito do Projeto Integrador e, neste caso, dos Projetos Integradores do curso, utilizando grupos de alunos com objetivos a serem atingidos de acordo com as competências de cada projeto integrador, trabalhando para um fim comum, que foi o desenvolvimento de uma solução para um problema ou desafio enfrentado por uma empresa do segmento, permitiu uma experiência real aos estudantes.

Ressalta-se, outrossim, que, a articulação dos professores foi fundamental para o sucesso da proposta, pois foi necessário que trabalhassem com um planejamento conjunto, minucioso e na perspectiva da identificação e responsabilização das entregas parciais para a concretização do projeto. Ou seja, cada professor, de cada Unidade Curricular que compõe o curso, atuou de modo a garantir que os estudantes tivessem condições de realizar as tarefas pelas quais ficaram responsáveis e nos prazos estabelecidos. Assim, o desenvolvimento das competências previstas em cada Unidade Curricular garantiu que o resultado fosse atingido.

Ressalva-se, entretanto, que, para desenvolvimentos futuros, recomenda-se ajustes no planejamento e na execução do projeto, para que os estudantes do primeiro módulo do curso se sintam amparados e em condições de encarar o compromisso requerido na entrega sob a sua responsabilidade.

Conclui-se, com a presente investigação, que o trabalho integrado e simultâneo de todos os Projetos Integradores do curso, realizados no âmbito do Laboratório de Práticas Profissionais, permitiu que os alunos tivessem experiências reais em todas as etapas de elaboração de um projeto de software para uma empresa. Essa situação, na qual cada módulo foi responsável pela elaboração de tarefas específicas e 
relacionadas às competências previstas a serem articuladas no respectivo módulo, permitiu a vivência da criação de um projeto de software em todas as suas fases e enfrentando as dificuldades que encontrarão quando se inserirem no mundo do trabalho, com o diferencial de estarem sob a supervisão e orientação de professores especialistas na área.

Nessa abordagem, os alunos tiveram a oportunidade de experimentar o trabalho em equipes com responsabilidades técnicas e hierárquicas, tratando situações de problemas concretos, que normalmente acontecem em equipes de desenvolvimento de projetos de software. Desse modo, os estudantes do curso de Análise e Desenvolvimento de Sistemas tiveram a possibilidade de, ainda durante a formação, atuar nas várias etapas do desenvolvimento de um serviço nessa área.

A riqueza da experiência para os estudantes não se restringiu apenas a atuar em determinada etapa do trabalho, pois, conforme explicado, cada turma atendeu às demandas relativas ao módulo que estava cursando, mas no compartilhamento do que cada grupo executava, ao participarem juntos das aulas em que todos acompanhavam o status de atendimento à demanda da empresa.

Pontua-se, também, como ganho e diferencial desta ação, a oportunidade que os estudantes do quinto módulo tiveram, qual seja, de acompanhar e verificar a produção dos colegas e assim validar o trabalho, já que eram responsáveis pelo gerenciamento do projeto.

\section{Notas}

${ }^{1}$ A Graduação Tecnológica em Análise e Desenvolvimento de Sistemas da Faculdade de Tecnologia Senac Rio prepara o aluno para projetar, especificar, desenvolver, documentar, testar, implantar e manter sistemas computacionais. O curso forma profissionais para trabalhar com ferramentas e equipamentos de informática, dominando a metodologia de gerenciamento de projetos na produção de sistemas informacionais (SENAC, 2019).

2 Projeto Integrador é o componente curricular que assegura a aplicação do conhecimento por meio da articulação das competências desenvolvidas em todas as Unidades Curriculares de cada módulo do curso, em situações com as quais o estudante se defrontará no mercado de trabalho.

${ }^{3} \mathrm{Na}$ Faculdade de Tecnologia Senac Rio, o curso é composto de 2.030 horas presenciais, distribuídas em cinco módulos. 


\section{Referências}

CONSELHO NACIONAL DE EDUCAÇÃO. Resolução n. 3, de 18 de dezembro de 2002. Institui as Diretrizes Curriculares Nacionais Gerais para a organização e o funcionamento dos cursos superiores de tecnologia. Diário Oficial da União: seção 1, Brasília, DF, ano 139, n. 247, p. 162-163, 2002. Disponível em: http://pesquisa.in.gov.br/imprensa/jsp/visualiza/index. jsp?data=23/12/2002\&jornal=1\&pagina=163\&totalArquivos=304. Acesso em: 17 out. 2018.

CORDÃO, Francisco Aparecido; MORAES, Francisco de. Educação profissional no Brasil: síntese histórica e perspectivas. São Paulo: Editora Senac São Paulo, 2017.

ELLIOT, Ligia Gomes; HILDEBRAND, Lucí; BERENGER, Mercêdes M. Questionário. In: ELLIOT, Ligia Gomes (org). Instrumento de avaliação e pesquisa: caminhos para construção e validação. Rio de Janeiro: Wak Editora, 2012. Cap. 1.

FREITAS, Wilma B. A.; NORI, Maria Teresa M. L2P: laboratório de práticas profissionais: a dimensão pragmática da aprendizagem. Rio de Janeiro: WalPrint, 2014.

MASI, Domenico de. 0 futuro do trabalho: fadiga e ócio na sociedade pósindustrial. 9. ed. Rio de Janeiro: José Olympio Editora, 2006.

MINAYO, Maria Cecília de Souza 0 desafio do conhecimento: pesquisa qualitativa em saúde. 10. ed. rev. e atual. São Paulo: Hucitec, 2006.

PERRENOUD, Philippe. Construir as competências desde a escola. Porto Alegre: Artmed, 1999.

REHEM, Cleunice Matos. Perfil e formação do professor de educação profissional técnica. São Paulo: Editora Senac São Paulo, 2009.

SENAC. Departamento Regional no Rio de Janeiro. Graduação Tecnológica em Análise e Desenvolvimento de Sistemas: sobre o curso. [2019]. Disponível em: https://www.rj.senac.br/faculdade-senac/graduacao/graduacao-tecnologica-emanalise-e-desenvolvimento-de-sistemas. Acesso em: 23 mar. 2019.

SILVA, Letícia Ester Cruz da. Acompanhamento metodológico dos instrutores e professores da educação profissional e tecnológica do Senac RJ: avaliação do processo. 2018. Dissertação (Mestrado Profissional em Avaliação) - Faculdade Cesgranrio, Rio de Janeiro, 2018. 